\title{
A Multi-Criteria Approach: For Empowerment to Enhancing Community Sustainable Development
}

\author{
Komal Choudhary ${ }^{1}$, Mukesh Singh Boori ${ }^{1,2,{ }^{*}}$ and Pavel Novacek ${ }^{1}$ \\ ${ }^{1}$ Palacky University Olomouc, 17. listopadu 50, 77146 Olomouc, Czech Republic \\ ${ }^{2}$ Geographical Institute, Ruhr University Bochum, Germany \\ "Corresponding author: Palacky University Olomouc, 17. listopadu 50, 77146 Olomouc, Czech Republic, E-mail: mukesh.boori@upol.cz
}

Received date: Nov 24, 2014, Accepted date: Nov 28, 2014, Published date: Dec 1, 2014

Copyright: (c) 2014 Choudhary K, et al. This is an open-access article distributed under the terms of the Creative Commons Attribution License, which permits unrestricted use, distribution, and reproduction in any medium, provided the original author and source are credited.

\section{Editorial}

\section{Proposed Outline of the Research}

For community sustainable development the concept is 'Think globally, act locally and plan regionally? Rural communities are the major entities in developing and third-world countries. While outsiders want to develop local community, they should develop the local conditions and sustain the result. In order to get sustainability among rural communities, technology becomes a booster to reach it. However, the success rates of many community development projects result only compare between to reach it. However, the success rate of many community Furthermore, when its result reaches sustainable condition of community development, many communities cannot further maintain as well as develop their sustainable development because low level of empowerment. This type of research work will attempt to develop conceptual framework how to reach the sustainable development in a community which was strengthened through the implementation of appropriate technology in order to reach empowerment. With the involvement of local residents, planners, and interest groups, a system model of more than 25 variables must be use.

\section{Introduction and Background}

In its most basic form, a sustainable community is one that can continue in a healthy way into an uncertain future. More formally, a sustainable community reflects the interdependence of economic, environmental, and social issues by growing and prospering without diminishing the land, water, air, natural and cultural resources on which communities depend. Housing, transportation and resource conservation are managed in ways that protect economic, ecological and scenic values.

The widespread popularization of proven appropriate technology techniques is very problematic and requires a concerted effort by everyone [1,2]. Three stages of logic in reaching community empowerment are given below:

\section{Development}

This is initial stage of development, when local people get some idea or support from theme self or outer for better life.

\section{Sustainable development}

This is the second stage of development. It's come after initial development. In this stage community maintain their initial development and still try for further growth with better method for better life.

\section{Empowerment}

This is final stage of development. In this stage local community is capable for good life with advance infrastructure. Now local community is independent and able to maintain them self by on.

The consensus in the wake of the United Nations Conference on Environment and Development (UNCED) suggests that the implementation of what has come to be known as "sustainable development" should be based on local-level solutions derived from community initiatives [3-5]. This reasoning comes with a long pedigree, dating at least from The Ecologist's "Blueprint for Survival", Schumacher's [6] "Small is Beautiful" and more recently, the Brundtland Commission [7,8] Statements of intent on global environmental problems issued following the 1992 Earth Summit, including Agenda 21 and the Desertification Convention, strongly advocate as solutions a combination of government decentralization, devolution to local communities of responsibility for natural resources held as commons, and community participation $[9,10]$. Such approach are helpful to better management of natural resources, their sustainable development so that they will utilize in future and will useful for local community, area at local to country level [11].

\section{Provisional Description of the Research}

\section{Study area and data:}

Study area: Rajasthan $\left(23^{\circ} 40^{\prime}-30^{\circ} 110^{\prime} \mathrm{N}, 69^{\circ} 290^{\prime}-78^{\circ} 170^{\prime} \mathrm{E}\right)$ is the largest state in India with a geographical area of 34.22 million ha (Figure 1). The regional climate varies from semi-arid to arid with average annual rainfall ranging from $480 \mathrm{~mm}$ to $750 \mathrm{~mm}$ with low values $(150 \mathrm{~mm})$ in the western arid region and $1000 \mathrm{~mm}$ in southeastern plateau. Pre-monsoon (April-June) is the hottest season of the year with temperature varying from $32^{\circ} \mathrm{C}$ to $45^{\circ} \mathrm{C}$. In western Rajasthan the air temperature often raises up to $48^{\circ} \mathrm{C}$ and the prevailing westerly winds cause dust storms locally known as "Andhi". During monsoon season (July-September), the area receives $90 \%$ of the annual rainfall; however, it often suffers from frequent drought due to poor and delayed monsoon rainfall, abnormally high summertemperature and insufficient water resources. The project has resulted in the improvement in agricultural production and regional development transforming the barren deserts of western Rajasthan into rich and lush fields for better living condition for the local people [12].

Data: In the present study, to take the dual advantages, both conventional and remotely sensed data can be used. The main remote sensing data products are: orbital images of Landsat TM, ETM+, IRS, Spot, IKONOS and SRTM data. Another ancillary data's are from 
metrology, climatology, agriculture, forest and survey departments such as geology and geography (topographic sheets of survey of India). In non-spatial data are demographic data, occupation data, and data related to amenities and general facilities, land and power availability etc. of the study area.

\section{Objectives}

1. The specific objective of this research work includes:

2. To empowered to advance rural initiative to access basic needs which can promote sustainable livelihood through self-reliance and community participation;

3. To promote self-sufficient development by their on-self for better life of local community;

4. To promote sustainable integrated community development with the rural communities through improving food security, promotion of saving culture, empowerment of women and safe motherhood, promotion of education and literacy, water and sanitation and climate change mitigation and adaptation;

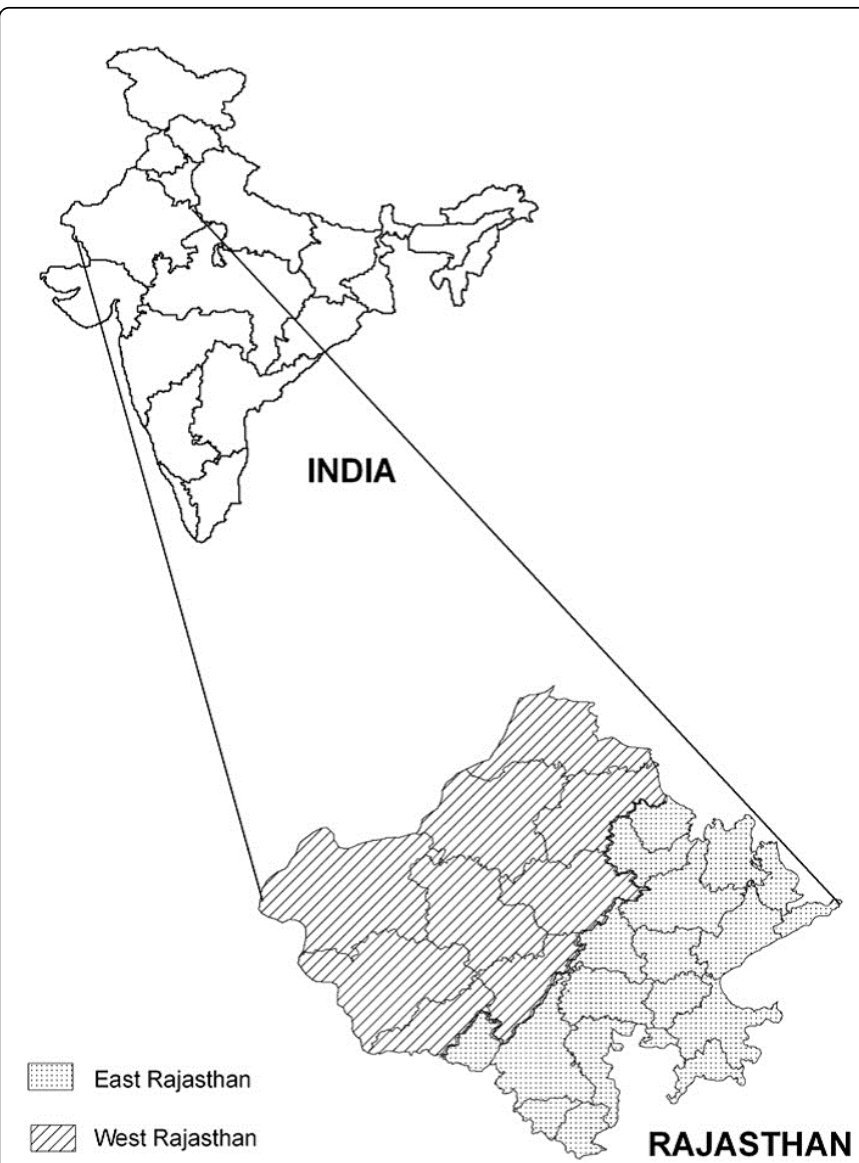

Figure 1: Location map of the study area.

1. To improve food security and household income in the rural;

2. To promote good health through increasing awareness on the causes of various diseases as well as promotion of safe motherhood (with much effort to the following diseases HIV/AIDS, Malaria and Tuberculosis);
3. To promote access to safe and portable water, good sanitation and hygiene using participatory methods;

4. To promote quality education, adult literacy programs and affordable vocational skills to the vulnerable youth and women

The main object of the community sustainable development is to achieve economic development, peace and security, and growth, alleviate poverty, enhance the standard and quality of life of the peoples, and support the socially disadvantaged through Regional Integration. These objectives must be achieved through increased Regional Integration, built on democratic principles, and equitable and sustainable development.

\section{Methodology}

This type of research proposals attempt to develop conceptual framework how to reach the sustainable development in a community which was strengthened through the implementation of appropriate technology in order to reach empowerment. The framework must be constructed through literature survey and then combined with several sample cases to provide a comprehensive discussion. We assume that empowerment is the next shape of sustainable development. Three stages of community development may reveal. Appropriate technology will be positioned as the bridging point in reaching empowerment of rural communities. By looking at previous efforts which treated sustainable development as the final purpose of community development projects, this type of research will gave new lights how to reach beyond it. Empowering rural communities and sustaining their sustainable development.

This research project consists of 4 distinct work-packages including reviewed literatures of each idea, which were about community empowerment, appropriate technology, and sustainable development (Figure 2). WP1 and WP2 focus on data collection and require fieldwork. WP3 and WP4 focus on data analysis and model building.

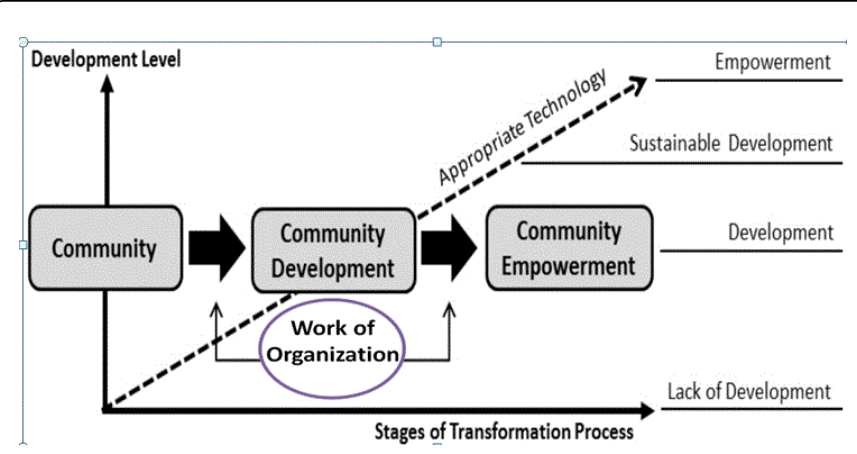

Figure 2: Theoretical framework.

WP1: Literature study and Compilation of past and present-day community information for sustainable development using multicriteria approach;

WP2: Collection of socio-economic, population and environmental data for community sustainable estimation

WP3: Identification of the main socio-economic and biogeophysical drivers for community sustainable development with ecosystem and there effects on society; 
WP4: To develop future community sustainable scenarios and evaluation of possible management strategies.

\begin{tabular}{|l|l|l|}
\hline Canals & Competition & Local Transportation \\
\hline Cultural activity & Water pollution & Accessibility to water resource \\
\hline Tourism crops & Waste treatment & Infrastructure \\
\hline Hiking trails & Recycling & Community conscience \\
\hline Local industry & Employment & Environment quality \\
\hline Marketing promotion & Culture industry & Local security \\
\hline Irrigation resource & Tourist turbulence & Local governance \\
\hline Agriculture & Traffic congestion & Education inputs \\
\hline Dependence on imported resource & Community image & \\
\hline
\end{tabular}

Table 1: System variables.

\begin{tabular}{|l|l|l|l|}
\hline Sector of Life & Phys. Category & Dynamic Category & System Relation \\
\hline Economy & Matter & Flow quantity & Open system to input \\
\hline Population & Energy & Structural quantity & Open system to output \\
\hline Land Utilization & Information & Temporal dynamics & Influenced internally \\
\hline Human Ecology & & Spatial dynamics & Influenced externally \\
\hline Natural Balance & & & \\
\hline Infrastructure & & & \\
\hline Communal Life & & & \\
\hline
\end{tabular}

Table 2: Criteria matrix.

Therefore, this type of study is able to answer following research questions:

What kind of technology that can be applied to solve community problem in reaching empowerment?

What is the appropriate conceptual framework that can be adapted to transform community development into community empowerment?

What efforts to outsiders do to sustain the sustainable development of rural communities and reach empowerment?

\section{Review of the work}

The need for community sustainable development for more socially, economically and environmentally sustainable systems of finance and exchange has never been more evident than it is at present, in the midst of a global economic and ecological crisis [13]. Conventional policy framings of sustainable development suggest ecological modernisation solutions based around market transformation and green growth [14,15] but these approaches have been criticised as inadequate in scope and ambition by academics [16], commentators [17] policy advisory bodies [18] and think tanks [19,20] for community sustainable development.
This type of research work can use following system variables (Table 1) and criteria (Table 2) for the study area but not limited: 
Citation: Choudhary K, Boori MS and Novacek P (2014) A Multi-Criteria Approach: For Empowerment to Enhancing Community Sustainable Development. J Geophys Remote Sensing 3: e110. doi:10.4172/2169-0049.1000e110

Page 4 of 4

12. Holmberg J, Thompson K, Timberlake L (1993) Facing the Future: Beyond the Earth Summit. IIED/ Earthscan, London.

13. Mellor M (2010) The Future of Money. Pluto Press London.

14. OECD (2011) Towards Green Growth: A Summary for Policymakers. OECD Paris.

15. Porritt J (2003) Redefining Prosperity: Resource Productivity, Economic Growth and Sustainable Development. Sustainable Development Commission, London.

16. Robertson J (1999) The New Economics of Sustainable Development: A Briefing forPolicymakers. Kogan Page, London.
17. Schumacher EF (1973) Small is Beautiful: A Study of Economics as if People Mattered. Blond and Briggs Ltd, London.

18. Spratt S, Simms A, Neitzert E, Ryan-Collins R (2009) The Great Transition. New Economics Foundation, London.

19. Stiglitz J, Sen A, Fitoussi JP (2009) Report of the Commission on the Measurement of Economic Performance and Social Progress.

20. UNEP (2011) Towards a Green Economy: A Synthesis for Policymakers. UNEP, Nairobi. 